
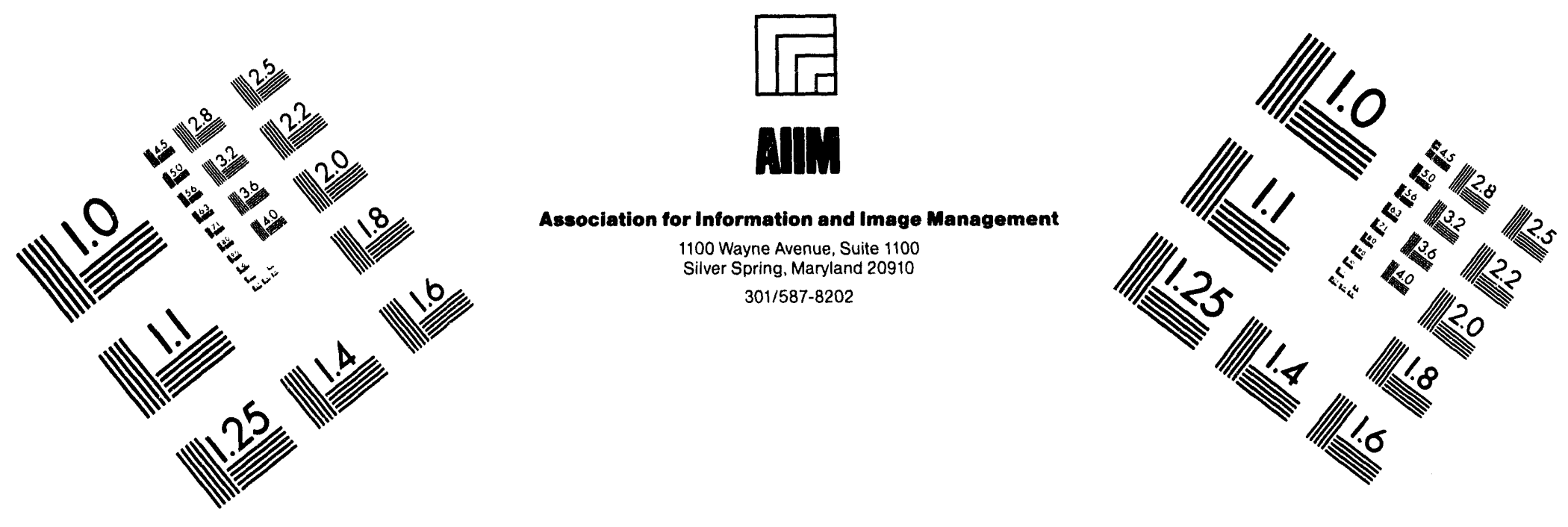

\title{
Centimeter
}

$\begin{array}{llllllllllllllll}1 & 2 & 3 & 4 & 5 & 6 & 7 & 8 & 9 & 10 & 11 & 12 & 13 & 14 & 15 & \mathrm{~mm}\end{array}$

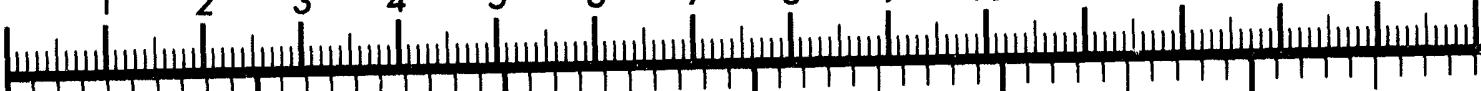

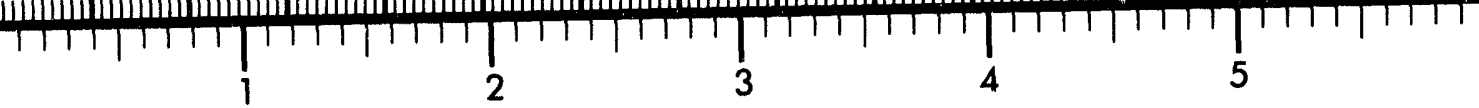
Inches
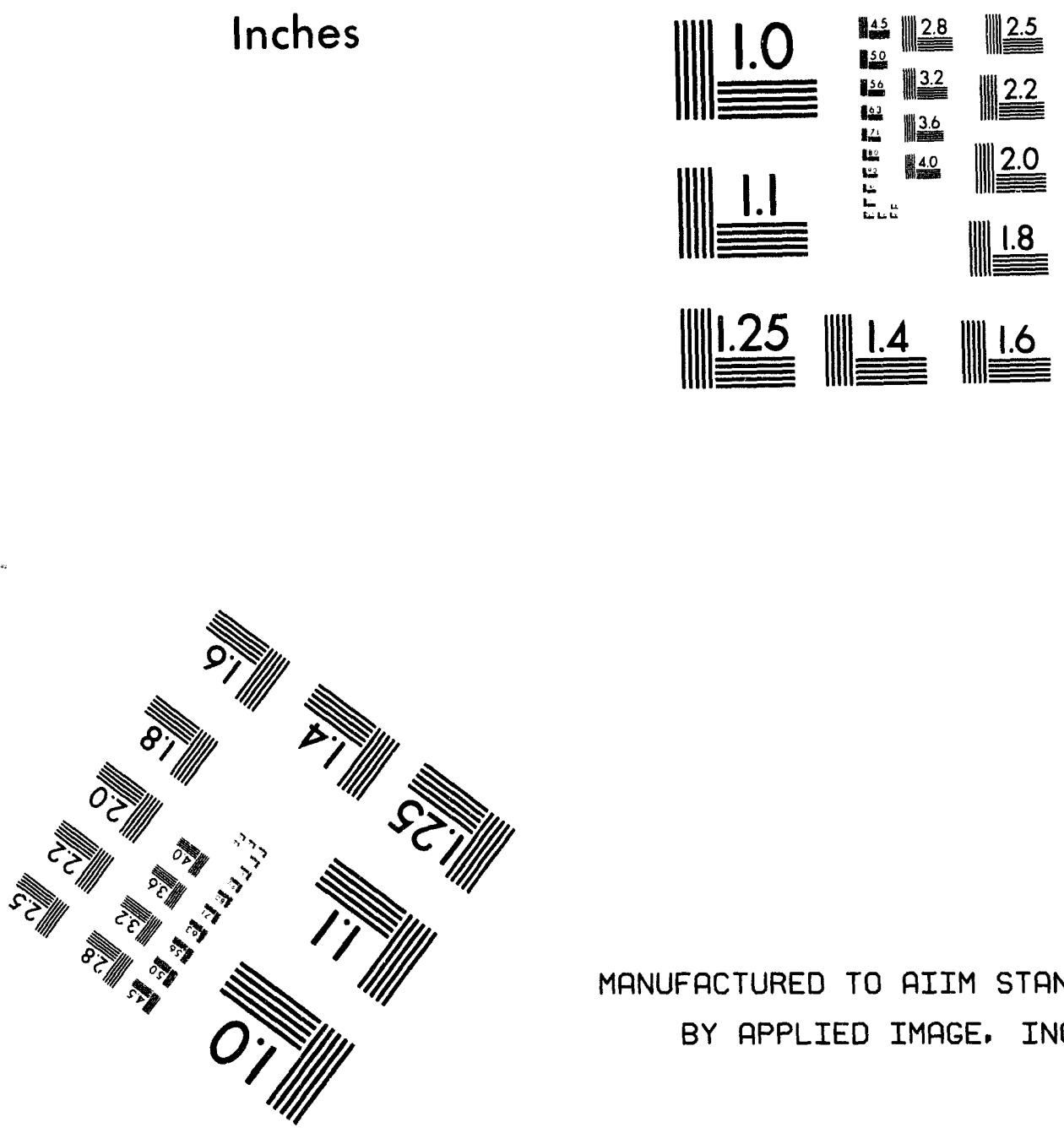

MANUFACTURED TO AIIM STANDARDS BY APPLIED IMAGE. INC.

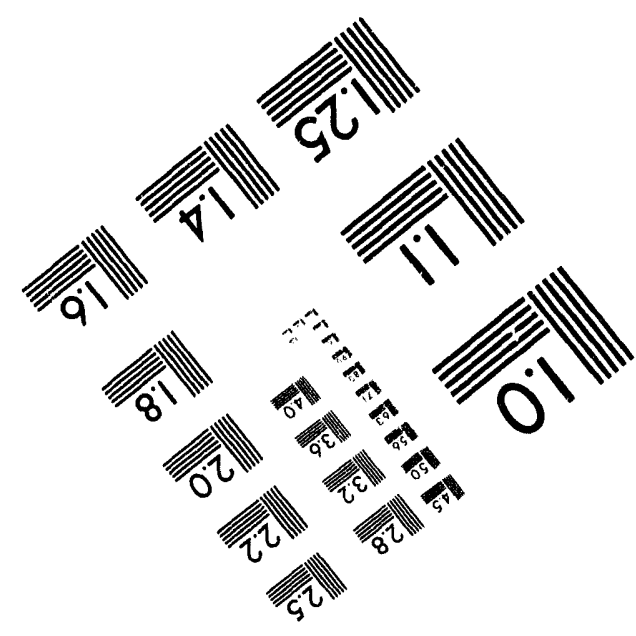



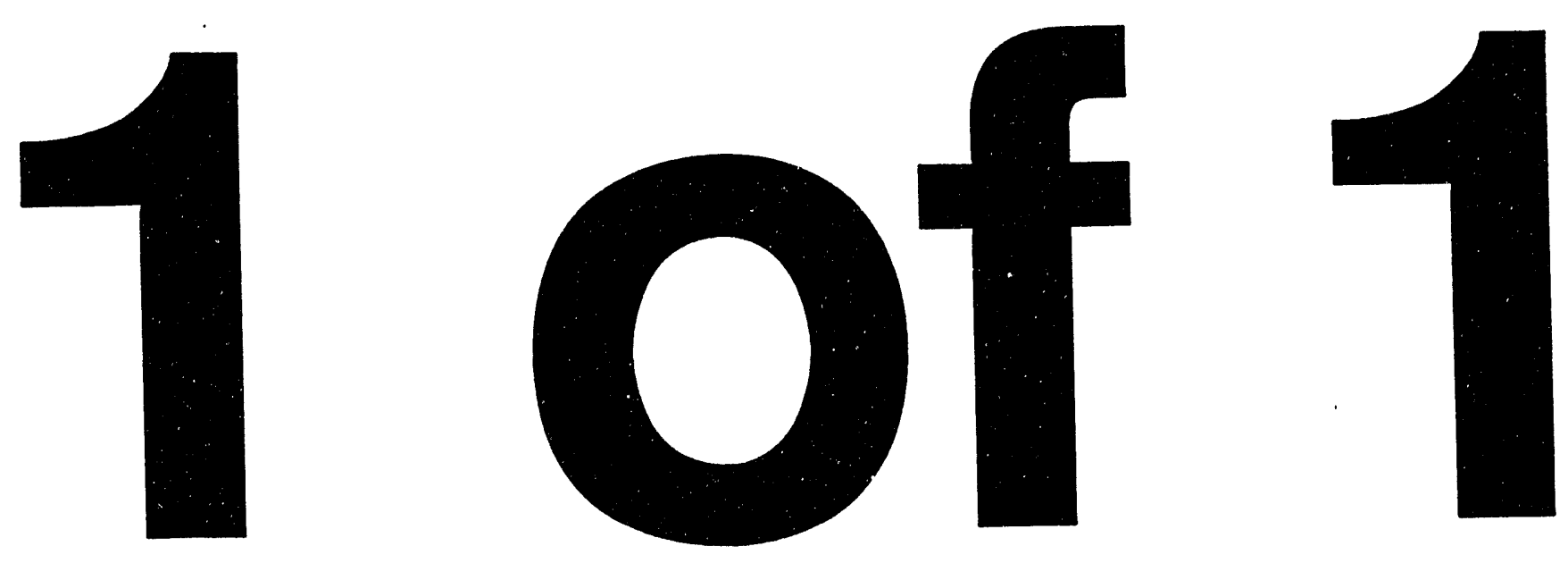
SAND94-8621

UC-406

\title{
Selecting the Best Defect Reduction Methodology-
}

\author{
C. Martin Hinckley \\ Project and Administration Department \\ Sandia National Laboratories / California \\ Professor Philip Barkan \\ Stanford University \\ Stanford, CA 94305-4021
}

\begin{abstract}
Defect rates less than 10 parts per million, unimaginable a few years ago, have become the standard of world-class quality. To reduce defects, companies are aggressively implementing various quality methodologies, such as Statistical Quality Control ${ }^{1,2}$, Motorola's Six Sigma ${ }^{3}$, or Shingo's poka-yoke ${ }^{4,5}$. Although each quality methodology reduces defects, selection has been based on an intuitive sense without understanding their relative effectiveness in each application. A missing link in developing superior defect reduction strategies has been a lack of a general defect model that clarifies the unique focus of each method.

Toward the goal of efficient defect reduction, we have developed an event tree which addresses a broad spectrum of quality factors and two defect sources, namely, error and variation. The Quality Control Tree (QCT) predictions are more consistent with production experience than obtained by the other methodologies considered independently.

The QCT demonstrates that world-class defect rates cannot be achieved through focusing on a single defect source or quality control factor, a common weakness of many methodologies. We have shown that the most efficient defect reduction strategy depend on the relative strengths and weaknesses of each organization. The QCT can help each organization identify the most promising defect reduction opportunities for achieving its goals.
\end{abstract}

\footnotetext{
* Based on a Journal article submitted to Quality and Reliability Engineering International
} 


\section{Table of Contents}

I. Introduction

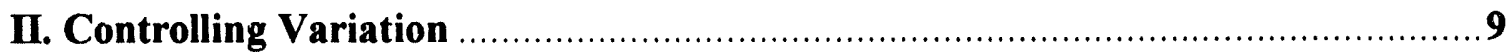

III. Error - a Distinctly Different Defect Source than Variation ............................10

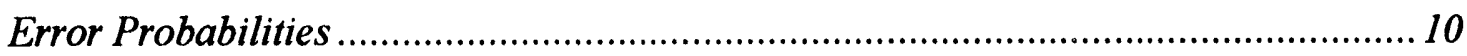

Probability-The Only Universal Method for Describing Error and Variation ............. 11

Error-A Critical Factor in Defect Creation.............................................................12

Poka-Yoke and 100 Percent Inspection ................................................................12

Relative Control of Error and Variation ............................................................... 13

IV. A Simple Model of a Manufacturing Process .............................................. 14

A Quality Control Tree (QCT) Model of a Process .................................................. 15

V. Assessment of Independent Quality Control Probabilities.................................17

Estimating Quality Control Probabilities Using Production Data................................ 17

Estimating Quality Control Probabilities Based on the Quality Control Methods...... 18

Estimating Event Tree Probabilities Through Inferences ............................................. 18

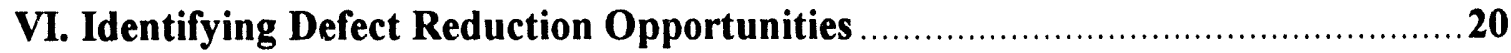

VII. Selecting Quality Control Improvement Methodologies ................................23

Defects are Underestimated by the Six Sigma Method.............................................. 23

VIII. The Quality Control Tree-A Superior Model of Quality Control.....................24

The QCT - A Better Model of Experience................................................................ 25

Additional Evidence Supporting the QCT Model......................................................25

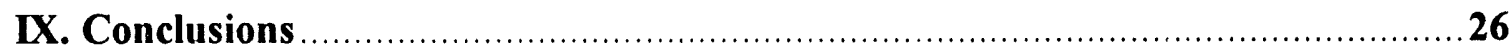

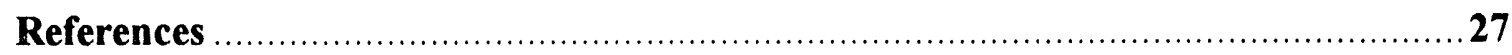




\section{List of Illustrations}

Figure

Page

1 Part proposed for the study of defects

2 A simplified representation of a manufacturing step

3 The Quality Control Tree (QCT) 16

4 Tornado diagram for quality control factor sensitivity 22

\section{List of Tables}

1 Quality factors in the Quality Control Tree 17

2 Typical values for event Probabilities in the Quality Control Tree 19

3 Predicted defect rate using typical event probabilities based on SQC 21

4 The relative effectiveness of adding different methodologies to SQC 24 


\section{Selecting the Best Defect Reduction Methodology}

\section{Introduction}

Our focus is motivated by the tremendous pressure to improve conformance quality, measured by the manufacturing defect rate, to previously unimaginable limits. Illustrating the required level of performance, Toyota ${ }^{6}$ asserted in 1990 that their North American suppliers had defect rates that were two orders of magnitude higher than their Japanese suppliers. Similarly, the goal of Motorola's six sigma ${ }^{3}$ program has been to reduce defects by roughly 3 orders of magnitude. In both cases the new target for defect levels is in the range of 1 to 10 parts per million (ppm). By contrast, defects in the range of 2,000 to $20,000 \mathrm{ppm}$ are perceived as normal using traditional Statistical Quality Control (SQC) ${ }^{1,2}$.

The consequences of this trend are profound, pointing to the need for a new rigor in understanding defects as an essential element for improvement. Several concepts and methods have evolved which have the purpose of reducing defects. The focus of these methods often leads to strategies for defect reduction that are limited, particularly when the goal is to achieve defect rates below $10 \mathrm{ppm}$. Furthermore, organizations often emphasize a single quality methodology which may not be the most effective for their particular strengths and weaknesses.

A clear understanding of the cause of defects is essential to efficient defect reduction. For this reason we will begin with a critical review of two of the main sources of product defects, variation and error. Building upon an understanding of the source of defects, a new model of the quality control process will be proposed.

\section{Controlling Variation}

Statistical Quality Control (SQC) was one of the earliest quality improvement methods to be developed. It has become the backbone of several other techniques like Motorola's Six Sigma $^{3}$ method and the Taguchi Method ${ }^{7}$. SQC is based on the principle that variation has been observed in all processes and that such variation can be described statistically. Building upon this concept, sampling methods have been developed to characterize process dispersion and control processes.

As typically applied in manufacturing control, the methods that focus on variation are based on three fundamental assumptions:

1) Sampling can be used to characterize all significant sources of variation,

2) All defects are a result of variation, and

3) The normal distribution can be used to describe most variation. 
Based on these assumptions, sample sizes are generally small. Additionally, outliers or "odd-ball" readings which do not appear to fit the observed population model are commonly discarded or discounted by group averaging ${ }^{1}$ in a manner that dilutes their significance. Such practices effectively preclude an accurate assessment of the "tails" or extreme values of a distribution.

Our work challenges the underlying assumptions that have lead to an excessive focus on the control of variation as the method for eliminating defects. Understanding the nature of rare events and the limitations of statistical methods is particularly important when the goal is to achieve defect rates below $10 \mathrm{ppm}$.

\section{Error - a Distinctly Different Defect Source than Variation}

Although variation is a useful way of describing the cause of many defects, it does not describe the cause of all defects. To illustrate, in the assembly of the simple box shown in Figure 1, an operator may occasionally forget to install a screw. In the assembly, each screw is either missing or present. Omitting a screw is an error. Errors are events that can only be described in terms of probability, which by their fundamental character are distinctly different than variation. We define error as either, 1) the execution of a prohibited action, or 2) the failure to perform a required action, or 3 ) the misinterpretation of information essential for the correct execution of an action. Illustrating the third type of error, an operator could alter a temperature setting inappropriately as a result of misreading a gage, or a machinist could remove too much material on the final machining pass as a result of misinterpreting a micrometer caliper.

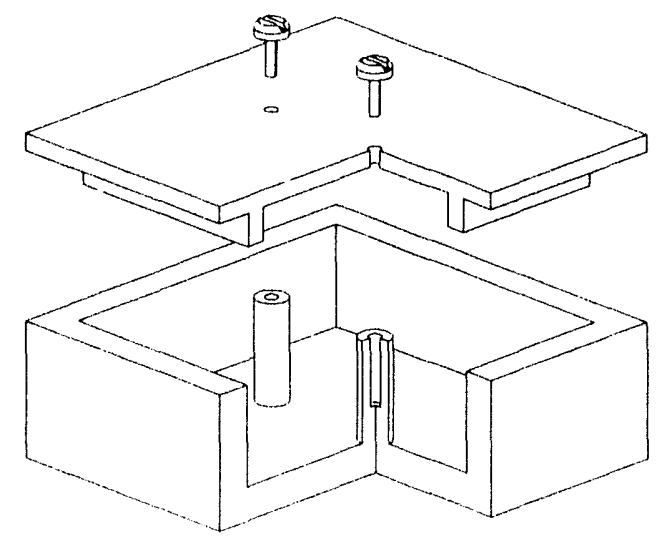

Figure 1. Part proposed by Olivera ${ }^{8}$ for the study of defects resulting from variation. Omitting a screw, an error, illustrates a type of defect that can not be described as variation.

\section{Error Probabilities}

Rook ${ }^{9}$ found, in a study of over 23,000 production defects, that the probability of failing to execute an operation and then failing to detect the omission using traditional production practice was approximately 0.00003 . In other words, roughly one operation in 
33,000 will be omitted without detection resulting in a defect rate of $30 \mathrm{ppm}$. Even though such omission errors occur rarely, variation models significantly underestimate the frequency and magnitude of the defects caused by these errors. For example, a tolerance of \pm 0.005 inches can be maintained when drilling half inch diameter holes, suggesting that the diameter standard deviation is about 0.0017 inches. Failure to drill a hole results in a diameter of 0.0 inches, a outcome that is 300 standard deviations from the mean which we would predict would never occur based on the variation paradigm. This prediction is completely inconsistent with Rook's observation of omission error rates.

Note that early detection of error, can often enable corrective action that avoids defects. A warning that notifies an operator that a required hole has not been drilled, for example, allows the operator to take corrective action before the part is removed from the drill press with a defect. This has important implications as will be discussed later.

There are many different types of error that can occur in addition to omission errors. For example, parts can be assembled in the wrong orientation, the wrong part may be assembled, an operator may process the wrong piece, or an operator might select the wrong process for a part or product ${ }^{10}$. Since many different types of error can occur, the defect rate resulting from errors often exceeds the world class goal of 1-10 ppm by orders of magnitude.

Traditional sampling and statistical methods are not useful in estimating the frequency of errors because errors are bimodal events that occur rarely in productic $n$. More importantly, statistical sampling methods are not effective in eliminating defects caused by errors. Because errors differ in basic nature from variation, errors require different methods of control, and consequently must be treated as a separate source of defects.

We have consistently found that traditional statistical methods underestimate the frequency and magnitude of rare events that are more than three standard deviations from the mean. This major discrepancy constitutes a critical limitation in predicting or controlling defect rates. Support for this assessment comes from our study of 23 independently observed distributions of human performance obtained from research and production environments ${ }^{11}$. Our work has revealed important and potentially common exceptions to the Central Limit Theorem. A model which more accurately accounts for rare events is based on Pareto's law.

\section{Probability-The Only Universal Method for Describing Error and Variation}

In lieu of traditional methods of statistical modeling, we begin by noting the we can convert every distribution describing variation to probabilities. We can use distributions to predict the probability of exceeding specification limits, or the probability of interference, however, we cannot convert every probability to a distribution.

As we have already shown, error can only be effectively described in terms of probability. Errors either occur or they do not. A part is either present in the product or missing. Consequently, the only universal method of describing both error and variation is probability. 


\section{Error-A Critical Factor in Defect Creation}

While each individual type of error occurs only rarely, collectively errors can have a significant impact on the product defect rate. Harris et al. ${ }^{12}$ concluded that 80 percent of the defects in complex systems could be attributed to error. In an examination of 23,000 production defects, Rook ${ }^{9}$ found that 82 percent of all defects were caused by human errors. Voegtlen ${ }^{13}$ reported that 60 percent of product failures could be traced to workmanship defects. In our review of data summarizing defects in front end automotive headlamps produced by a major manufacturer we observed that more than 70 percent of 6,600 observed defects were caused by assembly or handling errors ${ }^{11}$. In addition, NASA $^{14}$ reported that most of the space shuttle mishaps since October 1990 were the result of human error. All of these studies point to human error as a defect source that is at least equal in importance to variation.

In addition to human error, we must recognize the machine errors also occur. Such errors can arise from voltage spikes, a mis-oriented parts, or intermittent failures. Generally, machine errors occur less frequently than human errors.

\section{Poka-Yoke and 100 Percent Inspection}

Shingo ${ }^{4}$, who guided Toyota's production to world class defect rates, makes an important distinction between error and product defects. While errors are inevitable, defects are not. Defects are avoided if an error is found and corrected early. He has shown that, in many cases, simple methods can provide early error detection that assure correction before a defect is passed to the next stage in the production process. He stated:

"We should recognize that people are, after all, only human and as such, they will, on rare occasions, inadvertently forget things. It is more effective to incorporate a checklist-i.e., a poka-yoke-into the operation so that if a worker forgets something, the device will signal that fact, thereby preventing defects from occurring. This, I think, it the quickest road leading to attainment of zero defects. " (italics added)

This is consistent with Rasmussen's ${ }^{15}$ observations. He concluded that the frequency of defects derived from incident reports goes down as the opportunity for people to immediately detect and correct the errors goes up. Since no amount of vigilance or training can assure that all unintentional errors will be recognized, a better method of control is needed. A core concept is that poka-yoke $e^{4,5}$, or autonomous mistake-proofing, in combination with 100 percent inspection, can catch virtually every error.

Poka-yoke concepts are typically extremely simple. For example, in a hole drilling operation, a microswitch may be used to assure that the press has been actuated the correct number of times for each part. If the operator attempts to remove the part without plunging the right number of holes a warning alarm sounds. The simplicity of the inspection devices is an essential element of the cost effectiveness of $100 \%$ inspection.

Shingo ${ }^{4}$ stated in 1985, that "In general, the cost of constructing poka-yoke devices came to $¥ 30,000$ (\$150) or less. In expensive cases it was no more than $¥ 100,000$ (\$500) or so." 


\section{Relative Control of Error and Variation}

The most effective strategy for reducing defects is strongly dependent on their dominant source. In one plant, for example, more than 80 percent of the defects may be the result of errors, while in another plant less than 40 percent of the defects originate from this source. As a consequence, the best strategy for defect reduction at each plant will be fundamentally different.

A simple analogy will illustrate the importance of identifying the best defect reduction strategy. Imagine an leaky wooden water tank filled with water. The rate at which water is leaking from the tank is analogous to the defect rate. Water could be pouring from knot holes (errors) or seams (variation). How shall we most effectively reduce the water loss? The answer depends upon the rate of water loss from each source. If 80 percent of the water loss is from knot holes, focusing effort on sealing the seams is not very effective.

The way to reduce the rate of water loss most rapidly is to repeatedly locate and plug the largest leak (defect source) in various locations around the tank. As the major source of leaks is checked, even if the seal is imperfect, leaks in other locations around the tank become the dominant source of water loss that must be sequentially stemmed. The point is, modest efforts focused on the largest defect sources often achieve better results than a massive effort to eliminate a single defect source such as variation. To define the best defect reduction strategy, you must know the relative defect rates arising from the various defect sources for your product and respond accordingly.

This points to the need for a separate methodology or tool useful in characterizing and quantifying the quality control process. In this report we introduce an event tree based on the principles of Decision Analysis ${ }^{16}$ which aids in identifying the general strengths and weaknesses of the quality control methods used in production. 


\section{A Simple Model of a Manufacturing Process}

For this purpose, we begin with a model representing any manufacturing step involving a single process, which has elements of input, process, inspection, decisions, and output as illustrated in Figure 2. Materials, parts, equipment, and fixtures are typical of some physical inputs required to execute a process. Tool sharpness, feed rates, tool path definitions, and temperature control illustrate another class of required inputs. Ideally, the process that alters physical elements from an initial state to a more desired state will only be executed after all of the inputs are available, set, and deemed acceptable. Stamping, casting, molding, transporting, and assembly are examples of typical processes. The output represents the transformed state of the input elements after the process.

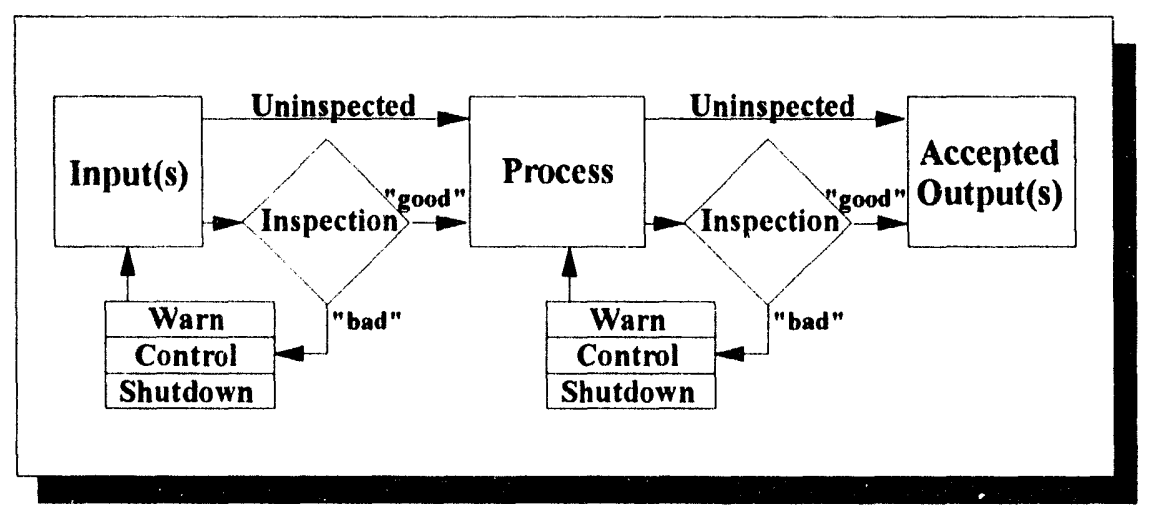

Figure 2. A simplified representation of a manufacturing step.

Excessive variation and errors in the inputs or process cause defects in the outputs. Inclusions in metals, voids in castings, and out-of-tolerance dimensions illustrate some defects that may be attributed to excessive input variation. Mishandling or dropping parts, clerical mistakes, or random voltage glitches represent some input errors leading to defects such as scratches, chips, or dents. Power fluctuations, vibrations, and cycle time variations reflect some process variations that can lead to unacceptable product. Misoperation is a process error that can result in defective product. The frequency of errors and excessive variation in each case can be described in terms of a probability of occurrence.

Based on traditional manufacturing process control methods, most inputs, processes, and outputs are not inspected. The probability of inspection is set by the practices of the organization, which, in many cases, is based on statistical sampling methods. In other organizations, poka-yoke is used extensively in conjunction with 100 percent inspection techniques. Even when poka-yoke techniques are used, however, these procedures can seldom be applied to every input, process, or output. As a result, there is always some probability that an input, process, or output will not be inspected.

When an input is uninspected, we are always willing to use the input as though it were defect free even when it is known that some fraction of the inputs may contain defects. Similarly, uninspected processes are executed, and uninspected output is passed to the 
next manufacturing step or to the customer. In this sense, we always tacitly assume the uninspected inputs, processes, and outputs are satisfactory until a defect or error is discovered.

Inspection reports either a "good" or "bad" condition. Since inspection is imperfect, the report, which is enclosed in quotation marks for distinction, may differ from the true state. When inspection reports a "bad" state or condition, one of three possible actions must be instituted according to Shingo ${ }^{5}$, namely: 1) shutdown, 2) control, or 3) warning.

\section{A Quality Control Tree (QCT) Model of a Process}

Building upon the methods of Decision Analysis ${ }^{15}$, an event tree for a single manufacturing step has been constructed to model events, decisions, outcomes, and processes. This event tree is shown in Figure 3. Because complex manufacturing processes are just a combination of many individual processes, we can use the simple inodel in conjunction with average event probabilities to represent any manufacturing cycle. The horizontal lines in the tree denote events, and the alphanumeric values on the connecting flow paths represent the probability that the event will occur. The probability of arriving at any particular event is equal to the cumulative product of the probabilities along all preceding paths leading to the event.

Three possible events are associated with input(s), designated by bad, error, and good. The bad event, a consequence of excessive variation, is an out-of-tolerance condition. An input error which will result in a defect is represented as an the error state. The good event represents a state that conforms to intent, it is free of excessive variation or an error. Generally, the probability of input errors $\left(e_{i}\right)$ or excessive input variation $\left(b_{i}\right)$ is small. As a result, there is a high probability that the inputs to any process will be good $\left(y_{i}\right)$. Process execution can also result in events which are bad $\left(b_{p}\right)$, error $\left(e_{p}\right)$, and $\operatorname{good}\left(y_{p}\right)$.

A few simplifying assumptions have been made in preparing this event tree. First, we have assumed that input defects are not eliminated by processing and may be detected by inspection after processing. Second, there is a small probability that outputs may contain multiple defects. The event tree could be expanded to address this condition but would become excessively complex. In this simple model, we assume that any product containing a single defect is defective and that the state is defined by the most severe defect. Finally, even with excessive variation there is some probability (1-d) that the product will still be defect free. For example, the probability of interference when assembling a cylinder in a mating hole depends on the joint probability that the cylinder will be too large and the hole will be too small. This probability is significantly less than the probability that either the hole or cylinder will exceed the tolerance limits. 


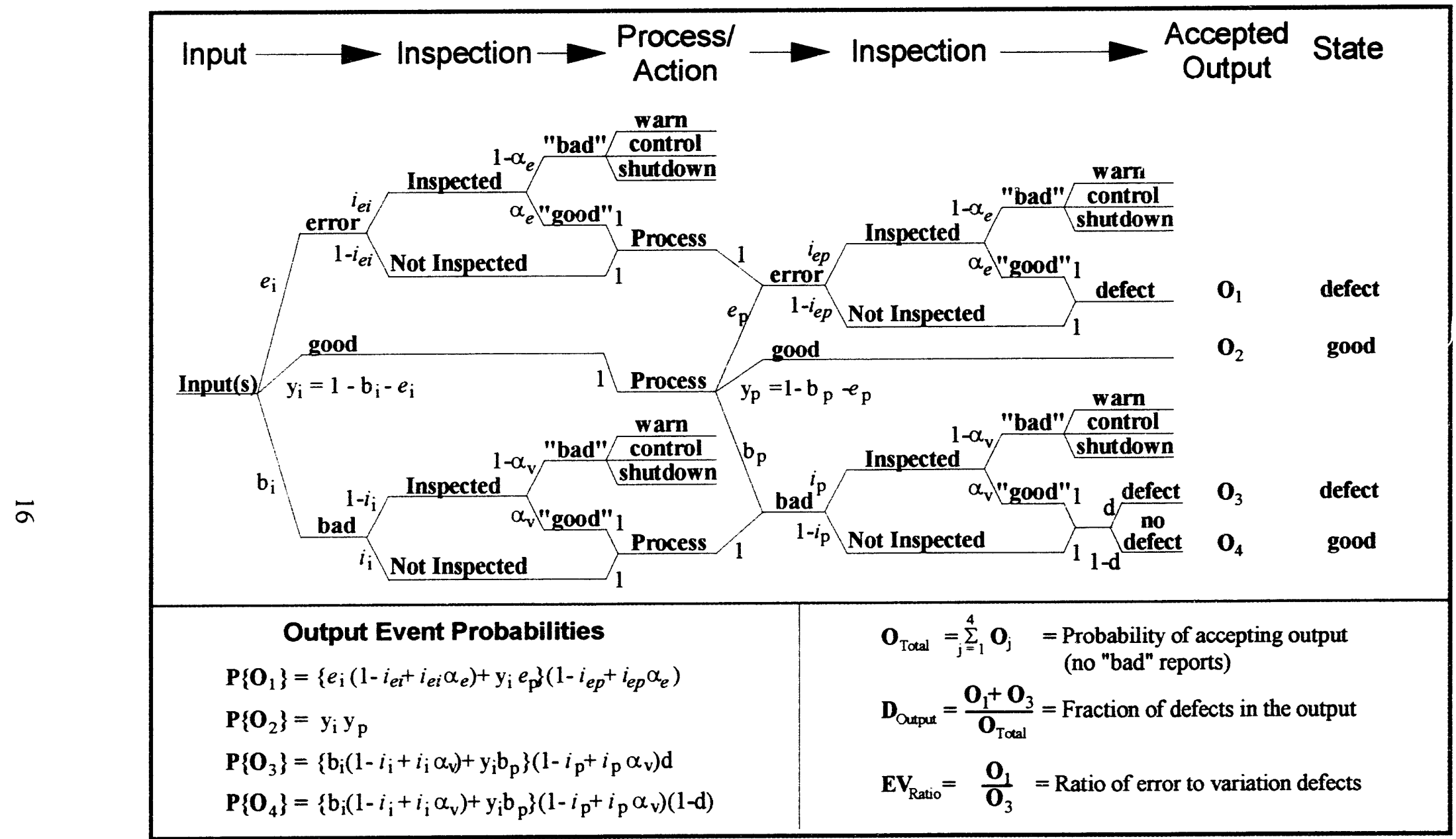

Figure 3. Quality Control Tree (QCT) for evaluating the relative strengths and weaknesses of each organizations quality control philosophy. A description of the event probabilities of this tree are provided in Table 1. 
In addition to control of variation this model addresses many factors that are often not considered in traditional Statistical Process Control, including, 1) errors, 2) the type of inspection, 3) the reliability of inspection, 4) the probability of inspection, and 5) the timing of inspection. Table 1 provides a description of the event tree probabilities used in Figure 3. In the mathematical shorthand shown in Table 1, "P" stands for the probability that the event enclosed in parenthesis occurs, and the vertical bar (|) is interpreted as "given that."

Table 1. Quality Factors in the Quality. Control Tree (QCT) model illustrated in Figure 3.

\begin{tabular}{|c|l|l|}
\hline $\begin{array}{c}\text { Quality } \\
\text { Factor } \\
\text { symbol }\end{array}$ & $\begin{array}{c}\text { Description of Quality Factor } \\
\text { Probability of... }\end{array}$ & \multicolumn{1}{|c|}{ Math Shorthand } \\
\hline$\alpha_{e}$ & error inspection failure & $\mathrm{P}\{$ “good"|error \& inspect for error $\}$ \\
$\alpha_{\mathrm{v}}$ & variation inspection failure & $\mathrm{P}\{$ “good"|bad \& inspect for bad $\}$ \\
$\mathrm{b}_{\mathrm{i}}$ & excessive input variation & $\mathrm{P}\{$ bad input $\}$ \\
$\mathrm{b}_{\mathrm{p}}$ & excessive process variation & $\mathrm{P}\{$ bad process $\}$ \\
$\mathrm{d}$ & defect given excessive variation & $\mathrm{P}\{$ defect|bad $\}$ \\
\hline$e_{\mathrm{i}}$ & input error & $\mathrm{P}\{$ input error $\}$ \\
$e_{\mathrm{p}}$ & process error & $\mathrm{P}\{$ process error $\}$ \\
$i_{e i}$ & inspection for input error & $\mathrm{P}\{$ input inspected for error $\}$ \\
$i_{e p}$ & inspection for output error & $\mathrm{P}\{$ process inspected for error $\}$ \\
$i_{\mathrm{i}}$ & inspection for input variation & $\mathrm{P}\{$ input inspected for variation $\}$ \\
$i_{\mathrm{p}}$ & inspection for output variation & $\mathrm{P}\{$ process inspected for variation $\}$ \\
\hline & Dependent Probabilities & \\
\hline $\mathrm{y}_{\mathrm{i}}$ & defect free input & $\mathrm{P}\{$ input is good $\}$ \\
$\mathrm{y}_{\mathrm{p}}$ & defect free process & $\mathrm{P}\{$ process output is good $\}$ \\
\hline
\end{tabular}

\section{Assessment of Independent Quality Control Probabilities}

The performance of each organization in specific quality control areas differs significantly. Identifying the greatest opportunities for reducing defects requires an assessment of quality control strengths and weaknesses for each organization or facility. This can be accomplished by assessing the event probabilities in the Quality Control Tree (QCT). Production data, the quality control methods, and inferences regarding the relationships between events are useful in estimating of the event tree probabilities.

\section{Estimating Quality Control Probabilities Using Production Data}

Ideally, production data would be used to estimate all of the probabilities in the Quality Control Tree for each organization. For example, data may be available on the reliability of inspection for variation $\left(\alpha_{v}\right)$, or the average defect rate of input parts $\left(\sim b_{i}\right)$ within a facility. Although production data is rarely adequate for estimating many of the required 
probabilities, the quality control philosophy of each organization and inferred relationships between the event can be used to estimate probabilities in the Quality Control Tree.

\section{Estimating Quality Control Probabilities Based on the Quality Control Methods}

The quality control methods used by each organization strongly influence many of the probabilities in the Quality Control Tree. For example, the probability of inspection for variation $\left(i_{i} \& i_{\mathrm{p}}\right)$ may be estimated directly from the sampling methods and general practices without requiring production data. Typical values for the event probabilities of several well known quality control methods are estimated in Table 2.

As Table 2 shows, each quality control method targets different specific improvement opportunities. Blank portions of the table reflect quality improvement areas where the various methods have little or no intended influence. For example, Motorola's Six Sigma ${ }^{3}$ concept does not address errors, inspeciion frequency, or inspection reliability. On the other hand, the goal of the Six Sigma method is to reduce defects to $3.4 \mathrm{ppm}$ through the control of process variation. Thus, the Six Sigma goal can be modeled by setting $b_{p}$ equal to $3.4 \mathrm{ppm}$.

The poka-yoke $e^{4,5}$ method, also listed in Table 2 , reduces the frequency of errors and provides a means of detecting and correcting errors when they occur. Due to the rare nature of errors, 100 percent inspection is required to control specific errors. However, poka-yoke techniques often can not be applied to every feature or action. Thus, the error inspection probability $\left(i_{e i} \& i_{e p}\right)$ describes the fraction of inputs and process elements controlled by poka-yoke. Note the distinctly different opportunities for defect reduction resulting from the application of the poka-yoke method and the Six Sigma method reflected in Table 2.

\section{Estimating Event Tree Probabilities Through Inferences}

Inferences about the relationship between events can also be used to estimate event probabilities and simplify the Quality Control Tree. For example, experience has shown that the probability of rejecting good inputs and processes through inspection is extremely small. Furthermore, our studies have shown that the defect rates are not sensitive to typical variations in this parameter. Thus, we have been able to omit inspection of good inputs and processes from the model with considerable simplification.

Deductive reasoning has also been useful in understanding the relationship between input and output defects. Since the output always represents a more complex state than the input, the output defect rate will generally be greater than the input defect rate. From this it can be shown that $D_{\text {Output }}$ is generally greater or equal to $b_{i}$. When quality control is consistently interpreted and manufacturers are striving to minimize defects, the defect rate of the output may approach, in the limit, the input defect rate $\left(D_{\text {Output }}=b_{i}\right)$. Thus, we can iteratively update $b_{i}$ until it converges with the value of $D_{\text {Output }}$ to approximate the best expected performance. 
Table 2. Typical values for event probabilities of several common quality improvement methods. (See the Event Tree Figure 3 and Table 1)

\begin{tabular}{|c|c|c|c|c|c|c|}
\hline & & \multicolumn{5}{|c|}{ Typical Event Probabilities } \\
\hline $\begin{array}{l}\text { Description of event } \\
\text { Probability of... }\end{array}$ & $\begin{array}{l}\text { Quality } \\
\text { Factor }\end{array}$ & $\begin{array}{l}\text { Traditional } \\
\operatorname{SQC}(3 \sigma)^{1,2}\end{array}$ & $\begin{array}{l}\text { Motorola } \\
\text { Six Sigma }\end{array}$ & $\begin{array}{l}\text { Poka- } \\
\text { yoke }\end{array}$ & $\begin{array}{c}\text { Source } \\
\text { Inspection } \\
4,5\end{array}$ & $\begin{array}{c}100 \% \\
\text { Inspection } \\
4.5\end{array}$ \\
\hline $\begin{array}{l}\text { error inspection failure } \\
\text { variation inspection failure } \\
\text { excessive input variation } \\
\text { excessive process variation }\end{array}$ & $\begin{array}{l}\alpha_{e}(1) \\
\alpha_{v} \\
b_{i}^{(4)} \\
b_{p}\end{array}$ & $\begin{array}{l}0.15 \\
0.15^{(3)} \\
\leq \mathrm{D}_{\text {Output }} \\
0.002^{(5)}\end{array}$ & $3.4 \mathrm{e}-6^{(6)}$ & $\begin{array}{ll}0.001 & (2) \\
0.001 & (2)\end{array}$ & 0.001 & $0.001^{(2)}$ \\
\hline $\begin{array}{l}\text { defect } \mathbf{w} / \text { excessive variation } \\
\text { input or process error } \\
\text { input or process error inspctn } \\
\text { input variation inspection } \\
\text { output variation inspection }\end{array}$ & $\begin{array}{l}\mathrm{d}^{(7)} \\
e_{\mathrm{i}}=e_{\mathrm{p}}^{(8)} \\
i_{e i}=i_{e p}^{(9)} \\
i_{\mathrm{i}} \\
i_{\mathrm{p}}\end{array}$ & $\begin{array}{l}0.3 \\
0.0004 \\
0.0004 \\
0.01^{(6)} \\
0.01^{(6)}\end{array}$ & & $\begin{array}{l}0.00004 \\
1(10)\end{array}$ & $1(10)$ & $1(10)$ \\
\hline
\end{tabular}

Notes: 1 . In the absence of measures to inspect for errors $\alpha_{e}=\alpha_{\mathrm{v}}$

2. Shingo's inspection methods have high reliability due to 1) autonomous execution, 2) process proximity, and 3) concept simplicity, but no data is available on reliability.

3. $P\{$ "good"|bad $\}\left(\alpha_{v}\right)$ is sensitive to product complexity ${ }^{12}$, number of process repetitions per product ${ }^{12}$, the defect rate, and the inspection pace ${ }^{17}$. Values between 0.01 to 0.80 have been reported, but the values in table is typical ${ }^{18,19}$.

4. Defect rates increase with product complexity. Therefore, the following relationship generally is true: $b_{i} \leq D_{\text {output }}$. (Note this requirement leads to iterative solution).

5. Sensitive to the lot size and defects discovered in sample.

6. Target defect rate from variation using Normal dist. per Motorola's Six Sigma ${ }^{3}$.

7. Assumed value held constant for all cases examined - No known general data.

8. Rook ${ }^{20}$ estimated error frequency to be about 0.0001 to 0.00001 per the "smallest behavior perceived as a unit." Processes typically require multiple behaviors with many failure modes leading to higher input and process error rates. Poka-yoke reduces error rates a significant but unknown amount.

9. In the absence of measures to inspect for errors, $i_{\theta i}=i_{\mathrm{i}} \quad \& \quad i_{e p}=i_{\mathrm{p}}$

10.(P\{inspection $\}=1)$ may only apply to a fraction of the inputs, outputs or features. Thus, $i_{e i} \& i_{e p}$ may be significantly less than 1 , even with $100 \%$ inspection methods.

An inspection for excessive variation will generally detect errors, if present. Thus in the absence of specific measures to inspect for errors, the probability of inspecting for errors is the same as the probability of inspecting for excessive variation $\left(i_{e i}=i_{\mathrm{i}} \& i_{e p}=i_{\mathrm{p}}\right)$ and probability of detecting an error is equal to the probability of detecting excessive variation $\left(\alpha_{e}=\alpha_{\mathrm{v}}\right)$.

These examples illustrate how the event probabilities describing the quality control performance of each organization can be estimated based on production data, each organizations quality control philosophy, and inferences. As shown in Table 2, the quality 
control methodologies utilized by each organization can strongly influence the event probabilities in specific areas, suggesting the opportunity for defining superior quality improvement strategies.

\section{Identifying Defect Reduction Opportunities}

The Quality Control Tree (QCT) in Figure 3 provides a means of combining the independent events probabilities to estimate the impact of quality control changes on the total defect rate. As illustrated by Figure 3, there are many different combinations of conditions that will result in output that is accepted. The QCT tree also clearly demonstrates that the fraction of defects in the accepted output ( $\left.D_{\text {Output }}\right)$ is a complex function of many quality control factors. Consequently, the quality improvement methods that focus on only a few factors can not achieve the highest levels of conformance quality demanded in today's competitive environment.

One of the potentially important values of the QCT is that it can be used to identify a quality control improvement strategy that maximizes improvement in the next product cycle for the level of invested effort. Defining such a strategy begins with an evaluation of the current company performance and a sensitivity analysis to identify the organization's strengths, weaknesses and opportunities.

To illustrate, independent event probabilities for each company besed on its current level of quality control are first determined, like those in Table 2. The event probabilities are substituted into the equations of Figure 3 . Some adjustment in the initial probability estimates may be required so that the defect rate predicted by the QCT approximately matches the production performance of the organization ( $D_{\text {Output }}=$ Observed Defect Rate). Using the SQC performance listed in the first data column of Table 2 to represent a hypothetical company's quality control performance a defect rate of $1960 \mathrm{ppm}$ is predicted as shown in Table 3. The ratio of error defects to variation defects $\left(\mathrm{EV}_{\text {Ratio }}\right)$ for this case is 0.67 , which indicates that three of five defects are a result of excessive variation.

The probability of each quality control factor in the baseline case can be varied independently to determine the sensitivity of the defect rate to each parameter. The range of variation for each quality control factor is arbitrarily taken as plus and minus one tenth of the difference between its nominal value and the ideal. The ideal for each quality control factor is probability that minimizes the defect rate. Maximizing inspection frequency $\left(i_{e i}=i_{e p}=i_{\mathrm{i}}=i_{\mathrm{p}}=1\right)$, for example, always minimizes the defect rate given that process control is not perfect. The ideal probability for all other independent quality control factors is zero. 
Table 3. Nominal value of quality control probabilities and predicted results for a hypothetical SQC baseline case (See the first data column in Table 2). The maximum and minimum values in the shaded portion indicate the range of the quality control factor used in sensitivity analysis.

\begin{tabular}{|c|c|c|c|}
\hline Quality Control Factor & $\begin{array}{c}\text { Nominal } \\
\text { Value }\end{array}$ & Min Value & Max Value \\
\hline$\alpha_{e}=\alpha_{\mathrm{y}}$ & 0.15 & 0.135 & 0165 \\
\hline$b_{p}$ & 0.002 & 0.0018 & 0.0022 \\
\hline $\mathrm{d}$ & 0.3 & 0.3 & 0.3 \\
\hline$e_{\mathrm{i}}=e_{\mathrm{p}}$ & 0.0004 & 0.00036 & 0,00044 \\
\hline$i_{e i}=i_{e p}=i_{\mathrm{i}}=i_{\mathrm{p}}$ & 0.01 & 0 & 0.109 \\
\hline $\mathrm{y}_{\mathrm{i}}=1-\mathrm{b}_{\mathrm{i}}-e_{\mathrm{i}}$ & 0.99764 & - & - \\
\hline $\mathrm{y}_{\mathrm{p}}=1-\mathrm{b}_{\mathrm{p}}-e_{\mathrm{p}}$ & 0.99760 & - & 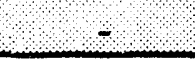 \\
\hline \multicolumn{4}{|c|}{ Predicted Results for Nominal Values } \\
\hline $\mathbf{P}\left\{\mathbf{O}_{1}\right\}=\left\{e_{i}\left(1-i_{e p}+i_{e i} \alpha_{e}\right)+y_{i} e_{p}\right\}\left(1-i_{e p}+i_{e p} \alpha_{e}\right)$ & 0.000789 & $\overline{\mathrm{O}_{\text {Total }}}=\Sigma \mathrm{O}_{\mathrm{i}}$ & 0.99994 \\
\hline $\mathbf{P}\left\{\mathbf{O}_{2}\right\}=y_{i} y_{p}$ & 0.995245 & $b_{i}=D_{\text {Output }}$ & 0.00196 \\
\hline $\mathbf{P}\left\{\mathbf{O}_{3}\right\}=\left\{\mathbf{b}_{\mathrm{i}}\left(1-i_{\mathrm{i}}+i_{\mathrm{i}} \alpha_{\mathrm{v}}\right)+\mathrm{y}_{\mathrm{i}} \mathbf{b}_{\mathrm{p}}\right\}\left(1-i_{\mathrm{p}} \mathrm{p}^{+} i_{\mathrm{p}} \alpha_{v}\right) \mathrm{d}$ & 0.001172 & $\mathrm{EV}_{\text {Ratio }}$ & 0.67 \\
\hline $\mathbf{P}\left\{\mathbf{O}_{4}\right\}=\left\{\mathrm{b}_{\mathrm{i}}\left(1-i_{\mathrm{i}}+i_{\mathrm{i}} \alpha_{\mathrm{v}}\right)+\mathrm{y}_{\mathrm{i}} \mathrm{b}_{\mathrm{p}}\right\}\left(1-i_{\mathrm{p}}+i_{\mathrm{p}} \alpha_{\mathrm{v}}\right)(1-\mathrm{d})$ & 0.002734 & & \\
\hline
\end{tabular}

In some cases, the allowable range of variation for a quality control factor is further constrained by the fact the probabilities must be between zero and one. For example, if the nominal probability of inspecting an input for excessive variation $\left(i_{\mathrm{i}}\right)$ is 0.01 , then the maximum probability would be $0.01+((1.0-.01) / 10)=0.109$, but the minimum probability must be 0.0 rather than $0.01-((1.0-.01) / 10)=-0.089$. The maximum and minimum range of probabilities examined for each factor in this case is given in Table 3.

A plot of the variation in defect rates for changes in each quality control factor sorted in order of sensitivity results in the "tornado" diagram shown in Figure 4. Here, sensitivity refers to the difference between the maximum and minimum defect rate given the change in a single quality control factor. The validity of the quality control assessment will be most strongly influenced by the probability estimates for the most sensitive variables. Hence, improved estimates of the nominal probabilities for the most sensitive variables may be desired, particularly if these probabilities are subject to the largest uncertainties. Figure 4 shows that the $\mathrm{dect}$ rate in this case is most sensitive to the probability of inspecting the process output for variation $\left(i_{p}\right)$, followed by the probability of excessive variation in the process $\left(b_{p}\right)$.

Note that some of the bars in Figure 4 are not symmetric about the nominal defect rate due to non-linear output equations and the probability limits mentioned previously. The bars extending furthest to the left in the figure show the changes that are most effective in reducing defects. Thus, even though the defect rate is more sensitive to $b_{p}$ in this case, changes in $i_{\mathrm{i}}$ provide a greater opportunity for reducing defects. As shown, the best method for reducing defects is not directly linked to sensitivity. Collectively, increasing the inspection frequency for input and process variation $\left(i_{\mathrm{p}} \& i_{\mathrm{i}}\right)$ offer the greatest defect 
reduction opportunities. This pattern suggests that Shingo's 100 percent inspection methods may be a particularly beneficial improvement strategy for this hypothetical company.

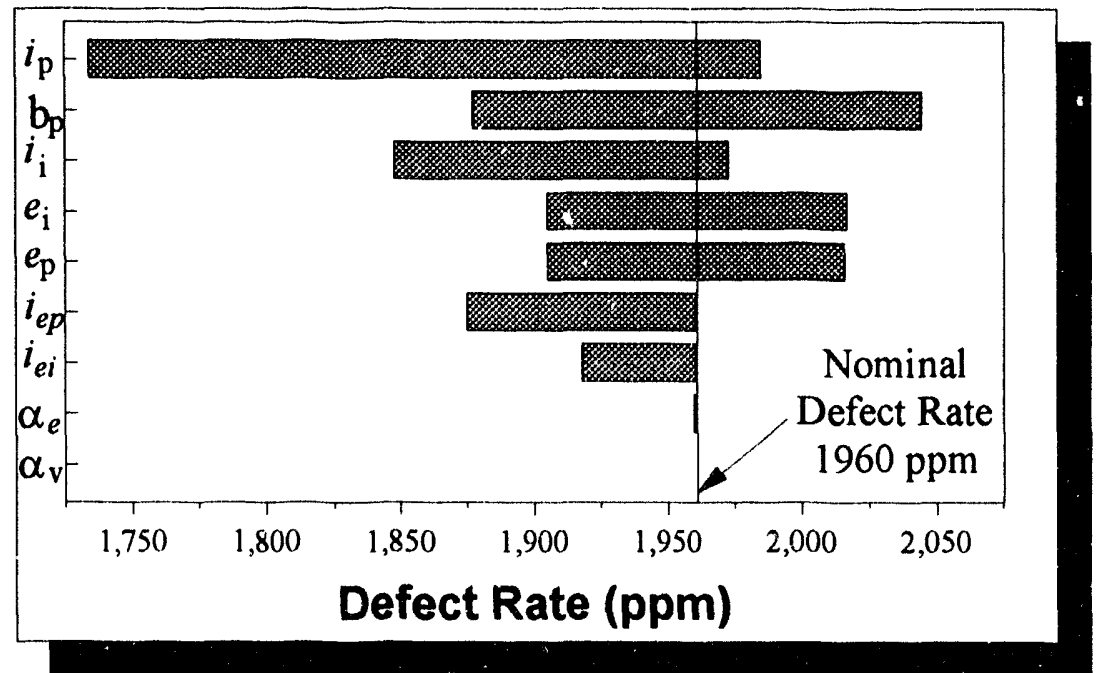

Figure 4. Tornado diagram illustrating the sensitivity of defect rate to changes in the probabilities of independent quality control factors. The range of variation for each parameter is \pm one tenth the difference between its nominal value and the ideal (where possible). For a detailed listing of the baseline condition see Table 3 .

The defect rate is more sensitive to the combined sum of the input and process errors $\left(e_{\mathrm{i}}+\right.$ $e_{\mathrm{p}}$ ) than to either the probability of input inspection $\left(i_{\mathrm{i}}\right)$ or the probability of excess process variation $\left(b_{p}\right)$ considered separately. Since estimates of error probabilities are likely to have the greatest uncertainty, control of errors should not be neglected in this example.

This type of analysis based on the QCT has identified the relative value of several distinctly different opportunities for improving quality control for this specific baseline case. Heretofore, such comparisons and insights have not been possible. The conclusions reached are unique to the nominal conditions which will vary from one organization to another. Although variation $\left(b_{p}\right)$ was a dominant factor in this example, controlling errors will have far more relative importance in many cases.

Although several basic defect reduction opportunities can be identified through the sensitivity analysis, the ability to respond fully is limited by company resources. Consequently, most companies can not apply equal effort to each opportunity, but must focus on one or two improvement methodologies in each product cycle. While sensitivity analysis aids in identifying critical quality control factors, the companies must also determine which methods they will emphasize and how much effort will be appilied to each method. Again, the QCT provides a powerful tool in making these decisions. 


\section{Selecting Quality Control Improvement Methodologies}

Given a specific schedule and budget, a company may have just enough resources to implement Motorola's Six Sigma ${ }^{3}$ method. As an alternative, for the same investment and schedule, company officials may feel that they could implement poka-yoke techniques for eliminating or controlling errors on 80 percent of the inputs and processes on the same product line. Conversely, the same effort dedicated to source inspection may permit 100 percent inspection on half of the inputs, or a similar level of effort may provide 100 percent inspection on one fourth of all inputs and processes.

Although each of the alternatives will reduce defects, the improvement achieved by each of these alternatives differs. Clearly, the preferred alternative is the method, or combination of methods which will maximize the reduction in defects for a given level of invested effort. The best strategy is strongly dependent upon each organizations quality control philosophy and current level of performance. In the past, selection of defect reduction methods have been based upon an intuitive sense that the methodology would reduce defects. The QCT enables an approximate relative comparison of the effectiveness of the proposed alternative methodologies in a manner that has been, heretofore, impossible.

Modification to the baseline defect rate can be evaluated by examining the effect of changing the event probabilities according to proposed changes in the quality control philosophy. For example, consider a strategy based on a "traditional" manufacturing philosophy and Statistical Quality Control (SQC) for a situation which is represented by the nominal probabilities in Table 3. In this case a defect rate of $1960 \mathrm{ppm}$ would be predicted as shown in the first column of Table 4. By replacing Statistical Quality Control (SQC) event probabilities with the appropriate Six Sigma event probabilities from Table 2 $\left(b_{p}\right.$ changes from 0.002 to $3.4 \mathrm{ppm}$ ), the impact of adding Motorola's Six Sigma method to the "baseline" SQC approach can be estimated.

\section{Defects are Underestimated by the Six Sigma Method}

In this example, the QCT model predicts that adding Motorola's Six Sigma method to a traditional SQC program would reduce defects from $1960 \mathrm{ppm}$ to $1120 \mathrm{ppm}$ as shown in the second data column of Table 4. Although the predicted improvement achieved by Six Sigma is substantial, this result is far less impressive than a defect rate of $3.4 \mathrm{ppm}$ projected by the Six Sigma philosophy. This result is also consistent with Motorola's experience $^{21}$. The difference in the Six Sigma and QCT predictions is greater than two orders of magnitude, which we attribute primarily to the influence of errors, a factor not addressed by Six Sigma.

In comparison to the predicted improvement to be achieved by implementing Six Sigma, by incorporating poka-yoke, defect rates could drop to $860 \mathrm{ppm}$. The source inspection alternative only reduces defects to $1430 \mathrm{ppm}$. However, applying 100 percent inspection methods would drop the defect rate to $720 \mathrm{ppm}$, achieving the lowest defect rate for the invested effort. Note that this result is consistent with the observation that the defect rate 
was most sensitive to the probability of inspection $\left(i_{\mathrm{i}} \& i_{\mathrm{p}}\right)$. From this we conclude that the best alternative considered in this example is implementation of 100 percent inspection. However, a better alternative might be a combination of two or more methods such as poka-yoke and 100 percent inspection methods.

Table 4. An illustration of the relative effectiveness of adding of several different quality control methods to a baseline SQC method using the event tree model shorv $n$ in Figure 3.

\begin{tabular}{|c|r|r|r|r|r|r|}
\cline { 2 - 7 } $\begin{array}{c}\text { Quality } \\
\text { Factor }\end{array}$ & $\begin{array}{c}\text { Traditional } \\
\text { SQC } \\
\text { Alone }\end{array}$ & $\begin{array}{c}\text { SQC }+ \\
\text { Six Sigma }\end{array}$ & $\begin{array}{c}\text { SQC }+ \\
\text { Poka-yoke }\end{array}$ & $\begin{array}{c}\text { SQC }+ \\
\text { Source } \\
\text { Inspection }\end{array}$ & $\begin{array}{r}\text { SQC }+ \\
\text { 100\% } \\
\text { Inspection }\end{array}$ & $\begin{array}{r}\text { Six Sigma } \\
+ \text { SQC }+ \\
\text { Poka-yoke }\end{array}$ \\
\hline$\alpha_{e}$ & 0.15 & 0.15 & 0.001 & 0.075 & 0.075 & 0.001 \\
$\alpha_{\mathrm{v}}$ & 0.15 & 0.15 & 0.15 & 0.075 & 0.075 & 0.15 \\
$\mathrm{~b}_{\mathrm{i}}$ & .001961 & .001121 & .000857 & .001432 & .000717 & .000024 \\
$\mathrm{~b}_{\mathrm{p}}$ & 0.002 & $3.40 \mathrm{E}-6$ & 0.002 & 0.002 & 0.002 & $3.4 \mathrm{E}-6$ \\
\hline $\mathrm{d}$ & 0.3 & 0.3 & 0.3 & 0.3 & 0.3 & .3 \\
$e_{\mathrm{i}}=\boldsymbol{e}_{\mathrm{p}}$ & 0.0004 & 0.0004 & 0.00004 & 0.0004 & 0.0004 & 0.00004 \\
$i_{e i}, i_{e p}$ & 0.01 & 0.01 & 0.80 & $0.5,0.01$ & 0.25 & .7 \\
$i_{\mathrm{i}}$ & 0.01 & 0.01 & 0.01 & 0.50 & 0.25 & .01 \\
$i_{\mathrm{p}}$ & 0.01 & 0.01 & 0.01 & 0.01 & 0.25 & .01 \\
\hline $\mathrm{y}_{\mathrm{i}}$ & 0.99764 & 0.99848 & 0.99910 & 0.99817 & 0.99888 & 0.99994 \\
$\mathrm{y}_{\mathrm{p}}$ & 0.99760 & 0.99960 & 0.99796 & 0.99760 & 0.99940 & 0.99996 \\
\hline Result $_{\mathrm{O}_{\text {Total }}}$ & 0.99994 & 0.99997 & 0.99990 & 0.99912 & 0.99941 & 0.99994 \\
$\mathrm{EV}_{\mathrm{Ratio}}$ & 0.67 & 2.38 & .01 & 0.74 & 3.14 & 1.96 \\
\hline $\mathrm{D}_{\text {Output }}$ & 0.00196 & 0.00112 & 0.00086 & 0.00143 & 0.00072 & 0.00002 \\
$\mathrm{D}_{\text {Output }}(\mathrm{ppm})$ & 1960 & 1120 & 860 & 1430 & 720 & 20 \\
\hline
\end{tabular}

\section{The Quality Control Tree-A Superior Model of Quality Control}

Previous research and methodologies have identified many factors that influence product quality including: a) variation (SQC \& Six Sigma), b) error frequency (poka-yoke), c) inspection frequency ( $100 \%$ inspection), d) inspection reliability, and e) inspection timing (source inspection). The lack of a comprehensive model which addresses all of these factors has been the critical missing link in defining effective defect reduction strategies. The unique contribution of the QCT is that it integrates all of the known defect sources and quality control factors in a common quantitative model for the first time. In this respect, the QCT is superior to any other known methodology considered independently. However, predictions based on the QCT are useful in guiding the quality improvement strategy only if they are consistent with production experience. 


\section{The OCT $=\underline{A}$ Better Model of Experience}

The previous example used to illustrate selection of a defect reduction alternative substantiates the validity of the QCT model. The Six Sigma concept is predicated on the assumption that defects can be reduced to the $3.4 \mathrm{ppm}$ level through the control of process variation. However, in the cited example the QCT predicted that Six Sigma control of process variation would only drop the defect rate to $1120 \mathrm{ppm}$. Given the large differences in the predicted defect rates, the Six Sigma method and the QCT model can not be equally valid descriptions of quality control. Motorola ${ }^{21}$ provided data for our study which can be used to identify which approach most accurately represents production experience. Using Six Sigma, Motorola's average defect rate per part for nine products was in the range of $800 \mathrm{ppm}$, which is of the same order of magnitude as the QCT predicted defect rate of $1120 \mathrm{ppm}$. This range of error is reasonable given our ability to estimate the event probabilities. By contrast, Motorola's observed defect iate is well nver two orders of magnitude larger than the Six Sigma predicted defect rate of $3.4 \mathrm{ppm}$.

Some may argue that Motorola has simply not achieved their Six Sigma goal. However, evidence that this is not the case can again be obtained from information published by Motorola:

"Motorola elected to enter this market (electronic ballast) and set a quality goal of 6 sigma for initial delivery. This required a very strict TDU (total number of defects per unit) budget. But it became evident early in the project that achieving a $\mathrm{C}_{\mathrm{p}}$ greater than 2 would go only part of the way. Mistake-proofing the design would also be required...Mistake-proofing the design is an essential factor in achieving the TDU goal. The design team is forced to investigate any opportunities for errors during mamufacture and assembly, and to eliminate them." 18 (italics adided)

Motorola's own experience clearly demonstrates that mistake-proofing (the English translation of poka-yoke $\mathrm{s}^{5}$ ) must be applied in conjunction with control of variation. As shown in the last column of Table 3, the predicted defect rate when poka-yoke techniques are combined with Six Sigma is $20 \mathrm{ppm}$. This QCT prediction is roughly consistent with Motorola's observed defect rates of tens of parts per million ${ }^{18}$ attained when they added mistake-proofing to their Six Sigma effort. Thus, the QCT provides a clearly superior description of quality control process than the Six Sigma method.

\section{Additional Evidence Supporting the QCT Model}

The QCT has yielded results which are consistent with production experience even when the insights were not obvious. For example, the model shows that inspection for variation can be eliminated $\left(i_{\mathrm{i}} \& i_{\mathrm{p}}=0\right)$ when excessive variation is extremely rare $\left(\mathrm{b}_{\mathrm{i}} \&\right.$ $b_{p} \Rightarrow 0$ ). This is consistent with the experience at Toyota where they have been able to eliminate SQC on the production floor after production startup for many processes while maintaining exceptionally low defect rates ${ }^{22}$. 
The QCT can be adapted and expanded to incorporate new quality improvement concepts as they evolve. Furthermore, the QCT can be modified to reflect each organization's unique conditions. As a result, the QCT is an extremely flexible tool that is relatively easy to use and understand. In combination with the insights and superior predictions afforded by the QCT, this model has the potential of being a powerful new tool in defining quality strategies that work.

\section{Conclusions}

Developing a sound strategy for improving product quality depends upon a method for identifying the strengths and weakness in conformance quality control. For this purpose a Quality Control Tree based on the principles of Decision Analysis ${ }^{16}$ has been defined. The results obtained using this model are consistent with the view Shingo ${ }^{5}$ and several studies that have shown that human error is a critical factor in product defects $9,11,12,13,14$.

However, the Quality Control Tree has shown that source inspection and 100 percent inspection must be combined with poka-yoke techniques to achieve the highest levels of quality control, a conclusion consistent with Shingo's Zero Quality Control Concepts'. The Quality Control Tree has also clarified the limitation of Motorola's Six Sigma ${ }^{3}$ method, providing estimates that are substantially more consistent with Motorola's own production experience.

The Quality Control Tree demonstrates that defect rates are a complex function related to the control of variation and error, as well as the type, timing, and reliability of inspection. As a consequence, there is no single quality tool which will assure the highest levels of quality performance. It has proven to be consistent with general trends observed in production, and provides useful distinctions in identifying the strengths and weaknesses of quality improvement methods.

Using this model, the current strengths and weaknesses of the quality control programs for any production line can be quantified in relative terms. A sensitivity study can be performed with minimum effort which aids in identifying the quality focus which will maximize the reduction in defects. The best method for reducing defects depends entirely on each organizations current strengths and weaknesses. Thus there is no common strategy that will be universally successful.

Although the Quality Control Tree is generally consistent in estimating the average defect rates and trends for a broad spectrum of products and quality methods, it can be very inaccurate in predicting defect rates for specific products. Quality control is a subset of the broader issue of conformance quality which must also address the impact of product complexity. Toward this goal, we have developed additional tools $\mathrm{s}^{11,23}$ which can be combined with the QCT to form a comprehensive conformance quality model. 


\section{References}

1. J. M. Juran and F. M. Gryna (eds), Juran's Quality Control Handbook, Fourth Edition, McGraw-Hill, New York, 1988., pp. 24.6.

2. K. Ishikawa, Guide to Quality Control, Asian Productivity Organization, Quality Resources, White Plains, Seventh Printing 1990.

3. M. J. Harry and R. Stewart, "Six Sigma Mechanical Design Tolerancing," Motorola Publication No. 6s-2-10/88, Scottsdale, AZ, 1988.

4. S. Shingo, Zero Quality Control: Source Inspection and the Poka-yoke System, Translated by Andrew P. Dillon, Productivity Press, Cambridge, Conn., 1986, p. 91.

5. Nikkan Kogyo Shimbun Ltd./Factory Magazine (edt), Poka-yoke-Improving Product Quality by Preventing Defects, Productivity Press, Cambridge, 1988 (English).

6. D. E. Sanger, 'U.S. Suppliers Get a Toyota Lecture', The New York Times, November 1, 1990.

7. P. J. Ross, Taguchi Techniques for Quality Engineering, McGraw-Hill, New York, 1988.

8. R. Olivera, ' 6 Sigma/Fit Tolerance Analysis', Communications Sector, Motorola Inc., Schaumburg. Ill., 1988.

9. L. W. Rook, Jr., Reduction of Human Error in Production, SCTM 93-62(14), Sandia National Laboratories, Division 1443, June 1962.

10. Y. Tsuda, 'Implications of Fool Proofing in the Manufacturing Process', Quality Through Engineering Design, Edited by W. Kuo, Elsevier, 1993, pp. 79-95.

11. C. M. Hinckley, A Global Conformance Quality Model - A New Strategic Tool for Minimizing Defects Caused by Variation, Error, and Complexity, Doctoral Dissertation for Stanford University Mechanical Engineering Department, Dec 1993.

12. D. H. Harris and F. B. Chaney, Human Factors in Quality Assurance, Wiley, New York, 1969 , p. 9.

13. H. D. Voegtlen, 'Complex Industries- Section 31', Juran's Quality Control Handbook, J. M. Juran, F. M. Gryna (eds), Fourth Edition, McGraw-Hill, New York, 1988., pp. 31.1-31.24.

14. The Associated Press, 'Space shuttle workers afraid to report errors, study finds', The Modesto Bee, Modesto, July 27, 1993.

15. J. Rasmussen, 'Trends in Human Reliability Analysis', Ergonomics, 28(8), 1985, pp. 1185-1195.

16. R.A. Howard and J. E. Matheson (eds), Readings on The Principles and Applications of Decision Analysis, Strategic Decision Group, California, 1989.

17. D. E. Chapman and M. A. Sinclair, 'Ergonomics in Inspection Tasks in the Food Industry', Human Reliability in Quality Control, C. G. Drury and J. G. Fox (eds), Halsted Press, 1975, pp. 231-251.

18. B. Smith, 'Making a War on Defects-Six Sigma Design', IEEE Spectrum, September, 1993, pp. 43-47.

19. R. McCornack, Inspector Accuracy: A Study of the Literature, Report SCTM-5361(24), Sandia Corporation, Albuquerque, 1961. 
20. L. W. Rook, Motivation and Human Error, SC-TM-135, Sandia National Laboratories, Albuquerque, September 1965, p. 5.

21. D. Gebala, Correspondence, Motorola, Inc., Advanced Manufacturing Technologies, Fort Lauderdale, FL, August 6, 1992.

22. T. Billings (NUMMI employee), Conversations w/ Martin Hinckley and Phil Barkan, February, 1993.

23. C. M. Hinckley, P. Barkan, "The Role of Variation, Error, and Commplexity in Manufacturing Defects," article Submitted to the Journal of Quality Technology, February, 1994. 
UNLIMITED RELEASE

\section{INITIAL DISTRIBUTION}

Susan Held

Co-Program Manager, Leadership Through Quality Staff

Albuquerque Operations Office

U. S. Department of Energy

P. O. Box 5400

Albuquerque, NM 87185-5400

Mark J. Kahnke

Director, Total Quality Management and Planning

AlliedSignal Inc., Kansas City Division, Mail Post 2A44

P.O. Box 419159

Kansas City, Mo. 64141-6159

Don E. Michel

President and General Manager

EG\&G Mound Applied Technologies, Inc.

P.O. Box 3000

Miamisburg, $\mathrm{OH} 45342-3000$

Melinda K. Bynum

TQM Director

Rocky Flats Plant

P.O. Box 464

Golden, CO 80402-0464

Anders W. Lundberg

Special Assistant for Weapons Safety Studies

Defense Technologies Engineering Division

Lawrence Livermore National Laboratories

P. O. Box 808, L-125

Livermore, CA 94551

Harry Flaugh

WX Deputy Division Leader

Los Alamos National Laboratories

WX-DO, MS P945

Los Alamos, NM 87545

Susan H. Alexander

Manager, Organizational Improvement Programs

Martin Marrietta Energy Systems, Inc.

Y-12 Site, Building 9119, Mail Stop 8236

Oak Ridge, TN 37831 
William F. Ierna

Director-Quality Assurance

Martin Marietta Specialty Components

P.O. Box 2908

Largo, FL 34649

J. C. Drummond

Division Manager, Quality

Mason \& Hanger -Silas Mason Co., Inc.

Building 12-28

P.O. Box 30020

Amarillo, TX 79177

Dennis L. Hayes

Manager, Tritium Program Coordinator

Westinghouse Savannah River Site

235- $\mathrm{H}$

P.O. Box 516

Aiken, SC 29802

MSTP

MS0112 P. M. Stanford, 10000

MS0141 M. R. Kestenbaum, 11000

MS0149 C. P. Robinson, 4000

MS0151 G. Yonas, 9000

MS0185 K. G. Haug, 10100

MS0186 C. E. Emery, 3000

MS0360 A. R. C. Westwood, 1000

MS0366 R. T. Johnson, 1040

MS0429 W. C. Nickell, 5100

MS0455 G. R. Otey, 4100

MS0463 R. L. Hagengruber, 5000

MS0491 R. E. Smith, 12333

MS0513 H. W. Schmitt, 2000

MS0517 M. Prickett, 2508

MS0637 E. M Austin, 12336

MS0638 M. A. Blackledge, 12326

MS0829 R. G. Easterling, 12323

MS0830 J. M. Sjulin, 12335

MS0830 K. K. Kern, 12335

MS0872 A. Beradino, 5408

MS0953 W. E. Alzheimer, 2900

MS1067 M. L. Jones, 7000

MS1357 A. A. Trujillo, 12913

MS1357 T. Olascoaga, 12914 


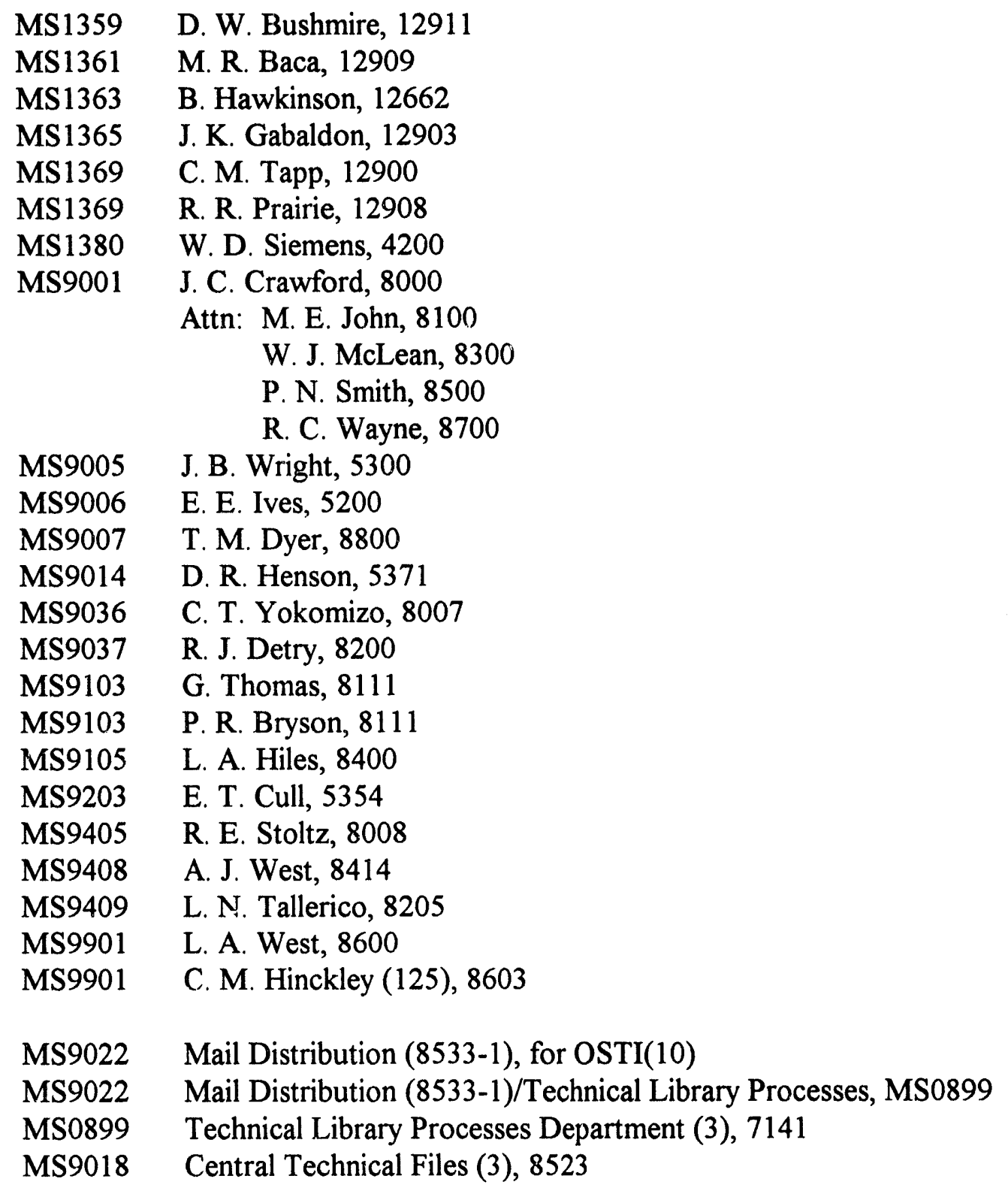



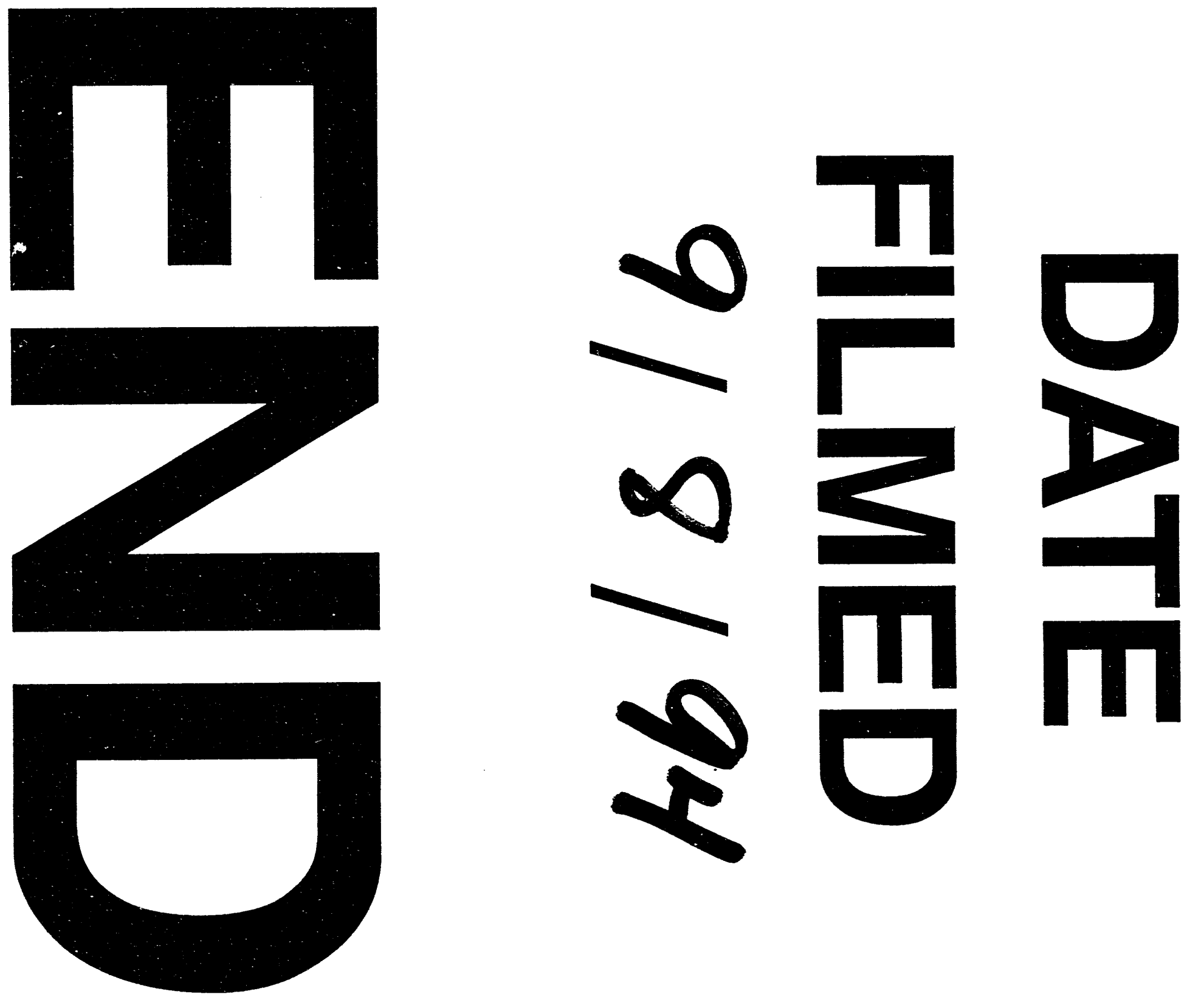
